\title{
25 Research Square \\ Evaluation of General Practitioners' awareness of hearing screening in the elderly
}

Jianli Ge

Zhongshan Hospital

Shasha Geng

Department of General Practice, Shanghai East Hospital, Tongji University School of Medicine

Qingqing Li

Department of General Practice, Shanghai East Hospital, Tongji University School of Medicine

Hua Jiang

Department of General Practice, Shanghai East Hospital, Tongji University School of Medicine

Xiaoming Sun ( $\nabla$ xm_sun2003@aliyun.com )

Zhongshan Hospital

\section{Research Article}

Keywords: The elderly, General Practitioners, Hearing screening, Presbycusis

Posted Date: November 2nd, 2021

DOI: https://doi.org/10.21203/rs.3.rs-970328/v1

License: (c) (1) This work is licensed under a Creative Commons Attribution 4.0 International License. Read Full License 


\section{Abstract \\ Objectives}

The aim of this study is to assess the awareness of community general practitioners on hearing screening for the elderly.

\section{Methods}

From January to February 2019, 367 general practitioners from 12 community health service centers, distributed in urban and suburban areas of Pudong District, Shanghai, were investigated with self-designed questionnaires.

\section{Results}

The general practitioners had poor understandings of the definition and onset of presbycusis. The accuracy of answers regarding the high-risk factors of presbycusis was zero. The top-three common hearing screening methods selected by general practitioners were screening version of the Hearing Handicap Inventory for the Elderly (HHIE-s) (94.55\%), self-auditory assessment (83.65\%), and pure-tone audiometry (77.66\%). As for the attitudinal evaluation of hearing screening, $49.59 \%$ of the participants thought it was highly meaningful, $48.77 \%$ thought that early intervention would have clinical benefits. However, $52.59 \%$ of the participants believed it was necessary for specialists to complete the auditory screening in the community, and $13.62 \%$ thought hearing screening was impracticable in community.

\section{Conclusion}

Our questionnaire suggested that general practitioners were aware of the knowledge of hearing screening and agreed with its significance. But further training is highly demanded to promote the professional skills for general practitioners in community.

\section{Introduction}

The aging of population is one of the most prominent demographic changes since the late twentieth century, becoming a severe challenge for many countries. The definition of presbycusis refers to the decline of auditory function caused by aging, which is the third of most common health condition affecting older adults after heart disease and arthritis ${ }^{[1-2]}$. The 2 nd WHO Cooperative Center for Deafness Prevention StrategicPlanConference disclosed that mild presbycusis could reduce communication and basic living abilities of the elderly and might even lead to depression or other psychological diseases in severe cases ${ }^{[3-4]}$. The prevalence of Alzheimer's disease in the elderly with mild, moderate, and severe hearing loss is twice, three, and five times higher than that of the elderly with normal hearing ability. It may even increase the risk of all-cause death in the elderly [2].

Presbycusis is characterized by symmetrical hearing loss in both ears at the initial stage, partly accompanied by tinnitus, which will ultimately lead to cognitive decline. Early screening and intervention for hearing loss in the 
elderly are expected to slow down the process, reduce the incidence of disability, and improve the quality of life ${ }^{[5-}$ 6].

Hearing screening for newborns has been carried out by primary health service centers for more than 20 years, achieving satisfying clinical results, while hearing screening for the elderly is still in its infancy [7-9]. The clinical standard hearing test and intervention technology model cannot consider both accuracy and cost-effectiveness. General practitioners undertake the task of non-infectious chronic diseases (NCDs) management for the elderly in the community. The management of presbycusis can refer to NCDs. Therefore, we hope to further evaluate the feasibility of community screening by general practitioners.

At present, there are many studies on the screening methods of presbycusis ${ }^{[10-12]}$ and the health beliefs of patients with hearing loss ${ }^{[13-14]}$, but there are few evaluations on the general practitioners' knowledge, beliefs, and practice of senile hearing screening. The purpose of our study is to evaluate the mastery of general practitioners in the knowledge of hearing screening for the elderly through a questionnaire survey and to provide basic guidance for the implementation and improvement of hearing screening in community.

\section{Methods}

\section{Participants}

Questionnaire was designed under the guidance of audiology experts. Thirty fifth general practitioners (unlimited nature) from each one of 12 community health service centers in Pudong New District, Shanghai, with a total of 420 , were recruited by convenience sampling method. Finally, 367 doctors provided effective questionnaires, and the response rate was $87.4 \%$.

\section{Questionnaire Design}

The questionnaire was comprised by four sections of force-choice scales, possible responses were the following: complete, basic, general, little, and no agreement.

The first section: general information

Gender, age, educational background, occupation, length of service, whether receiving general practice continued training, etc.

The second section: knowledge related to presbycusis

According to relevant books such as "Auditory rehabilitation of the elderly" [15] and "Basic and Clinical Audiology" [16], assessment of knowledge related to presbycusis was made from five aspects: definition, morbidity, diagnosis, high-risk factors, and harmful consequences.

The third section: knowledge of hearing screening for the elderly

Including detection and treatment of presbycusis, appropriate means in community, and methods of early intervention.

The fourth section: necessity of hearing screening for the elderly in community 
Including self-attitude and awareness of presbycusis, frequency of hearing screening, clinical benefits of hearing screening, whether general practitioners need to receive specialist training in otolaryngology, and whether to organize continuing sub-specialty education and the general practitioners' attitude towards conducting hearing screening

\section{Data collection}

Two investigators from Shanghai East Hospital who had been trained before the survey were responsible for the unified interpretation of the contents and options of the questionnaire individually. If there was any dispute about the results, the designer of questionnaire would make the final judgment. The unqualified questionnaires, with more than $5 \%$ of the core data missing, were rejected. The final questionnaire data was then extracted and doublechecked for the analysis.

\section{Data analysis}

The questionnaire is designed by Wenjuanxing software, and the data is analyzed by SPSS 25.0 statistical software. Continuous variables are represented by mean $\pm S D$, and categorical variable are represented by frequency and rate.

\section{Reliability and Validity of the questionnaire}

Reliability analysis refers to the degree of consistency of the results of repeated measurements of the same object using the same method. Reliability indicators are mostly expressed by correlation coefficient, which can be roughly divided into three categories: stability coefficient (consistency across time), equivalence coefficient (consistency across forms) and internal consistency coefficient (consistency across projects). The higher the reliability coefficient is, the more reliable the measurement is. Cronbacha is the most used reliability coefficient. Cronbach a coefficient greater than 0.60 is considered reliable ${ }^{[7]}$. In this study, Cronbach a coefficient is used to test the internal consistency of questionnaire setting.

The content validity of the questionnaire was evaluated by the four experts (audiologist from Shanghai East hospital and Punan hospital) according to the standard judgment method and the items with low content validity had been deleted ${ }^{[8]}$. The procedure includes three steps: (1) determine the number of experts ( $\geq 3$ ). (2) Experts evaluate the scale setting and dimensions, that is, whether the evaluation setting is complete and accurate, whether the content is consistent with the research objectives, and whether the setting can fully reflect the research scope.

\section{Results}

\section{Evaluation of reliability and validity}

The internal reliability was evaluated through Cronbach's alpha coefficient. As a result, it was calculated to be 0.7 (Table 1). The validity analysis was judged by four experts, and the scale and the content validity ratio were also calculated. 
Table 1

Reliability statistics

\begin{tabular}{|lllll|}
\hline & $\begin{array}{l}\text { Cronbach's alpha } \\
\text { after Item Deletion }\end{array}$ & $\begin{array}{l}\text { Cronbach's } \\
\text { alpha }\end{array}$ & $\begin{array}{l}\text { Cronbach's alpha } \\
\text { based on standardized } \\
\text { items }\end{array}$ & $\begin{array}{l}\text { Number } \\
\text { of } \\
\text { items }\end{array}$ \\
\hline Definition of presbycusis & 0.7 & 0.665 & 0.7 & 9 \\
\hline Morbidity of presbycusis & 0.7 & & & \\
\hline Awareness rate of presbycusis & 0.7 & & & \\
\hline $\begin{array}{l}\text { what will the elderly with hearing loss } \\
\text { they do? }\end{array}$ & 0.7 & & & \\
\hline Significance of hearing screening & 0.6 & & & \\
\hline $\begin{array}{l}\text { Appropriate frequency of hearing } \\
\text { screening }\end{array}$ & 0.6 & & & \\
\hline Clinical benefit of hearing screening & 0.6 & & & \\
\hline $\begin{array}{l}\text { Attitude toward continuing education } \\
\text { and training for General Practice }\end{array}$ & 0.6 & & & \\
\hline $\begin{array}{l}\text { Attitude toward sub specialist } \\
\text { training }\end{array}$ & 0.6 & & & \\
\hline
\end{tabular}

\section{Demographic Categories Across The Study Population}

There were 87 males and 280 females among all the general practitioners, with $4.25 \%$ of them aged $20-30,34.06 \%$ of them aged $30-40,34.6 \%$ of them aged $40-50$, and $7.08 \%$ of them aged over 50 . Education background tips: Bachelor's degree or below accounted for $86.65 \%$, Graduate degree accounted for $13.35 \%$ separately. For the work seniority, $33.24 \%$ of them had 1 to 5 -year work experience, $11.72 \%$ of them had 5 to 10 -year work experience, $16.35 \%$ of them had 10 to 15 -year work experience, and $38.69 \%$ of them worked for more than 15 years. The proportion of general practitioners who have received continuing general practice in the past five years was $73.39 \%$. In addition, the proportion of those who obtained the title of attending doctor or above was $67.8 \%$. As whole, the selected practitioners covered different ages, work seniorities, and educational levels (Table 2). 
Table 2

Demographic categories across the study population

\begin{tabular}{|ll|}
\hline Characteristics & Combined sample(n=367) \\
\hline Sex & $87(23.7 \%)$ \\
Female & $280(76.3 \%)$ \\
\hline Education background & \\
below Bachelor degree & $23(6.3 \%)$ \\
Bachelor degree & $295(80.4 \%)$ \\
Graduate degree & $49(13.4 \%)$ \\
\hline Age(years old) & \\
$20-30$ & $89(24.3 \%)$ \\
$30-40$ & $125(34.1 \%)$ \\
$40-50$ & $127(34.6 \%)$ \\
$>50$ & $26(7.1 \%)$ \\
Work seniority(years) & \\
$1-5$ & $122(33.2 \%)$ \\
$5-10$ & $43(11.7 \%)$ \\
$10-15$ & $60(16.4 \%)$ \\
$>15$ & $142(38.7 \%)$ \\
received general practice continuing education & $269(73.3 \%)$ \\
\hline Title & $118(32.2 \%)$ \\
Resident & $221(60.2 \%)$ \\
Attending & $28(7.6 \%)$ \\
Deputy director or above & \\
\hline
\end{tabular}

\section{Evaluation Of Mastery Of The Practitioners In Relevant Knowledge}

Among all the selected general practitioners, $78.48 \%$ of them had general or at least basic knowledge of the definition of presbycusis, while $54.22 \%$ of them had little knowledge or even knew nothing about the incidence of presbycusis. $66.67 \%$ of the senior practitioners had full understanding of the above knowledge. Unfortunately, nobody made the right choice among the high-risk factors of presbycusis (Table 3-4). However, more than $80 \%$ of the general practitioners knew the adverse consequences of presbycusis (Table 5). The correlation analysis had 
then conducted based on the above data, suggesting that the overall awareness was positively correlated with the title and the work seniority with the corresponding Pearson coefficient of 0.109-0.152.(Table 6).

Table 3

Definition and incidence of Presbycusis

\begin{tabular}{|llllll|}
\hline & $\begin{array}{l}\text { Fully } \\
\text { understanding }\end{array}$ & $\begin{array}{l}\text { Basic } \\
\text { understanding }\end{array}$ & $\begin{array}{l}\text { General } \\
\text { understanding }\end{array}$ & $\begin{array}{l}\text { Little } \\
\text { understanding }\end{array}$ & $\begin{array}{l}\text { Not } \\
\text { understanding }\end{array}$ \\
\hline Definition & $18[4.9 \%]$ & $123[33.5 \%]$ & $147[40.1 \%]$ & $73[19.9 \%]$ & $6[1.6 \%]$ \\
\hline Incidence & $4[1.1 \%]$ & $69[18.8 \%]$ & $95[25.9 \%]$ & $182[49.6 \%]$ & $17[4.6 \%]$ \\
\hline
\end{tabular}

Table 4

High- risk factors of Presbycusis

\begin{tabular}{|lllllllll|}
\hline & Diabetes & $\begin{array}{l}\text { Hyper- } \\
\text { lipedema }\end{array}$ & $\begin{array}{l}\text { Hyper- } \\
\text { uricemia }\end{array}$ & $\begin{array}{l}\text { Hyper- } \\
\text { tension }\end{array}$ & $\begin{array}{l}\text { Hypo- } \\
\text { thyroidism }\end{array}$ & Drug & $\begin{array}{l}\text { Cognitive } \\
\text { impairment }\end{array}$ & environment \\
\hline $\begin{array}{l}\text { Right } \\
\text { answers } \\
(\%)\end{array}$ & 309 & 211 & 138 & 275 & 6 & 31 & 28 & 264 \\
\hline
\end{tabular}

Table 5

Adverse consequences of presbycusis

\begin{tabular}{|lllll|}
\hline & Emotional disorders & Fall events & Cognitive impairment & Disability \\
\hline Right answers (\%) & 339 & 296 & 334 & 349 \\
& {$[92.7 \%]$} & {$[80.7 \%]$} & {$[91.0 \%]$} & {$[95.1 \%]$} \\
\hline
\end{tabular}

Table 6

Pearson correlation analysis about overall awareness

\begin{tabular}{|c|c|c|c|c|c|c|}
\hline & $\begin{array}{l}\text { Whether } \\
\text { screenin } \\
\text { elderly r } \\
\text { (over 60 } \\
\text { is of clin } \\
\text { significa }\end{array}$ & $\begin{array}{l}\text { earing } \\
\text { of } \\
\text { idents } \\
\text { ears old) } \\
\text { al } \\
\text { ce? }\end{array}$ & $\begin{array}{l}\text { What is the } \\
\text { most } \\
\text { significant } \\
\text { early } \\
\text { intervention } \\
\text { for } \\
\text { presbycusis }\end{array}$ & $\begin{array}{l}\text { Early } \\
\text { intervention } \\
\text { of } \\
\text { presbycusis } \\
\text { will have } \\
\text { clinical } \\
\text { benefits }\end{array}$ & $\begin{array}{l}\text { Do you agree } \\
\text { with the } \\
\text { implementation } \\
\text { of sub specialist } \\
\text { training for } \\
\text { general } \\
\text { practitioners }\end{array}$ & $\begin{array}{l}\text { What is your } \\
\text { attitude towards } \\
\text { hearing screening } \\
\text { for the elderly in } \\
\text { community health } \\
\text { service centers }\end{array}$ \\
\hline \multirow{2}{*}{$\begin{array}{l}\text { Education } \\
\text { background }\end{array}$} & $-.020 *$ & $.110 *$ & $.007 *$ & & $.011^{*}$ & $-.057^{\star}$ \\
\hline & $.699 \star \star$ & $.035^{\star *}$ & $.898^{\star \star}$ & & $.835^{\star \star}$ & $.272^{\star \star}$ \\
\hline \multirow{2}{*}{$\begin{array}{l}\text { Work } \\
\text { seniority }\end{array}$} & $.023^{\star}$ & $.115^{\star}$ & $-.006 *$ & & $.109 *$ & $-.021^{\star}$ \\
\hline & $.660 \star *$ & $.028 * *$ & $.912^{\star \star}$ & & $.038^{* *}$ & $.692^{\star \star}$ \\
\hline \multirow[t]{2}{*}{ Title } & $.110^{*}$ & $.126^{*}$ & .042 & & $.152^{\star *}$ & .015 \\
\hline & $.036 * *$ & $.015^{\star *}$ & $.418^{\star \star \star}$ & & $.003^{* *}$ & $.767 \star \star$ \\
\hline
\end{tabular}


Among the five screening methods in the questionnaire, the top three popular choices are the HIEE-s (94.55\%), Self-

auditory assessment (83.65\%), and Pure-tone audiometry (77.66\%), which are more recognized recently [9,17-19]

(Figure 1). As for the general practitioners' understandings of the treatment methods for hearing loss in the elderly, the major four methods selected were audiphones, installation of the electronic cochlea implants, hyperbaric oxygen therapy, and psychotherapy. The result (Figure 2) suggested that the general practitioners had general understandings of the diagnosis and treatment of hearing loss in the elderly and were able to make preliminary recommendations.

\section{Assessment of Attitudes to Screening}

The stratified analysis of screening attitude evaluation was conducted, and the results show: 1) Only $7.36 \%$ of the general practitioners agreed that elderly residents had complete or at least basic knowledge of presbycusis, $18.53 \%$ of general practitioners considered that when hearing loss occurs, the elderly would go to community health service centers for help, while $32.15 \%$ of them believed they would go to comprehensive hospitals. 2) About $70 \%$ of the general practitioners thought hearing screening for the elderly certainly had clinical benefits and $52.29 \%$ of them agreed that screening should be carried out in community. 3) HHIE-s and pure-tone audiometry were more recommended by the participating general practitioners than subjective faces scale, Whispered voice test, ${ }^{[17,20]}$. 4) As for the intervention methods towards hearing loss, hearing screening, health check-up, and health record management are the three common items suggested by general practitioners.5) "Would you suggest that general practitioners carry out continuing education and training in ENT at present", $32.24 \%$ of the general practitioners chose "complete agreement", 36.24\% of them chose "basic agreement", $22.07 \%$ chose "general agreement",7.63\% chose "little agreement", and $1.63 \%$ of them chose " no agreement". 6) Only $41.96 \%$ and $9.26 \%$ of general practitioners completely or basically agreed to implement sub professional training. As whole, more than $50 \%$ of the general practitioners agreed that hearing screening should be carried out at primary health centers. Therefore, they agreed that early intervention can be generally achieved through regular hearing screening, physical examination, and health record management. But both elderly and general practitioners were not fully aware of the demand for hearing screening, thus further training on basic understandings of presbycusis is highly required.

More than $50 \%$ of general practitioners agree to hearing screening in primary health care centers. They also recognized early intervention through regular hearing screening, physical examination, and health education. However, the elderly and general practitioners are not fully aware of the importance of regular hearing screening at the grass-roots level, so it is necessary to further strengthen professional training and health education.

\section{Discussion}

Nowadays, hearing loss is associated with many co-morbidities, including poorer physical health, anxiety, depression, loneliness, and isolation ${ }^{[21-24]}$. Despite its high prevalence, which has a significant negative impact on the quality of life and social burden, hearing loss has not been adequately treated.

According to data from the Centers for Disease Control of (USA) in 2013 , less than a quarter of the elderly received hearing screening. There is no unified data of the elderly in China ${ }^{[25]}$. In the United States, only one in seven adults aged 50 and older used hearing aids, with fewer than 1 in 20 working adults aged $50-70$ years doing so [26]. The number of studies on hearing aid use and its related factors is extremely limited in developing countries [27]. Nearly one-third of the hearing loss patients believed they were in sub-health state, while only $9 \%$ of normal-hearing patients considered they might be in poor health ${ }^{[28]}$. Findings suggest that hearing loss has a negative impact on 
independence levels and thus quality of life in older people as they heavily rely on family and their community for support ${ }^{29]}$. Perhaps earlier detection and diagnosis of hearing loss would allow for more successful treatment and

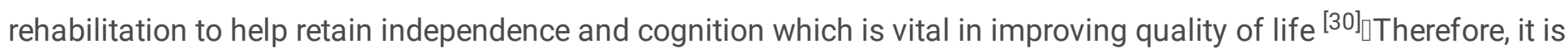
highly required for us to pay attention to presbycusis.

At present, most studies focus on the mechanism of hearing loss and the development of portable and simple hearing screening tools ${ }^{[31-32]}$. The existing hearing screening mode need to be further optimized in the aspects of human and material costs, professional requirements, object compliance, specificity, and sensitivity of screening. General practitioners can provide clinical care, prevention, treatment and decision-making between doctors and patients. They are the suitable people to implement technologies which can reduce medical costs and health system costs ${ }^{[33-34]}$. For the elderly, hearing screening by general practitioners in community is a good choice.

The questionnaire results showed that only $18.53 \%$ of general practitioners thought that community health service center should be the first choice for hearing loss of the elderly. Although they basically agree with the significance and intervention value of hearing screening for the elderly, but their willingness to screen is not synchronous, and their views on the implementation strategy are not the same. We need to further explore the reasons and accessibility measures.

In 2020, World Organization of National Colleges (WONCA) applied post competency to the field of general practice, and proposed "WONCA tree model", including 6 general practitioners' competency, which are as follows: primary care management, community orientation, Specific problem-solving skills, comprehensive approach, personcentered care, holistic approach. By 2020, China had initially established a general practitioner system, and basically formed a unified and standardized general practitioner training mode and the service mode of first visit at primary medicine. However, the training mode of general practitioners is not perfect. The training of general practitioners is mainly focused on internal medicine and health management, but the knowledge of Ophthalmology, pediatrics, ENT, gynecology, dermatology and so on is truly little. At the same time, our questionnaire also reflects that the self-confidence of general practitioners is not high, and only $41.96 \%$ have a strong desire to obtain all kinds of specialist training. Therefore, the implementation of multi-channel continuing medical education (CME) will improve the comprehensive ability of general practitioners and promote their self-confidence, which is an important foundation for the implementation of hierarchical diagnosis and treatment, the realization of chronic disease management and the promotion of healthy aging ${ }^{[35]}$.

In addition, we need to consider the following points so as to promote the general practitioners carrying out hearing screening for the elderly actively. First, we should establish a performance system to link the workload and income of hearing screening. Secondly, we need to evaluate the cost-effectiveness of hearing screening, including technical cost, labor cost, case cost, false-positive cost, etc. Therefore, the hearing screening of the elderly in the community depends on the further resources and financial support of the government.

\section{Strengths And Limitations}

The questionnaire was designed by us.

The subjects were general practitioners.

The questionnaire involves three aspects: knowledge, attitude, and practice. 
Only some urban areas participated in the questionnaire.

The conclusion of the questionnaire has certain promotional significance. It is suggested to increase participants from different regions and backgrounds.

\section{Abbreviations}

Not applicable.

\section{Declarations}

\section{Ethics approval and consent to participate]}

Not applicable.

Ethics Committee of Shanghai East Hospital, Tongji University School of Medicine Approval No. [2019] No. 028 My submission was performed in accordance with the Declaration of Helsinki .

\section{Consent for publication:}

Written informed consent for publication was obtained from all participants.

\section{Availability of data and material:}

All data generated or analyzed during this study are included in this published article and its supplementary information files. All authors agree to the data sharing.

\section{Conflicts of Interest:}

The authors have no competing interests.

\section{Funding:}

Scientific research project of Shanghai Health and Family Planning Commission (201940235)

\section{Authors' contributions:}

JLG: the conception and design and write of the work

SSG: collection and interpretation of data

QQL: analysis and interpretation of data

$\mathrm{HJ}$ : the conception and design of the work

XMS: substantively revised and approve the submitted version

ALL authors have read and approved the manuscript and ensure that this is the case 
Acknowledgments:

The authors express thanks to Professor Jirong Duan from Hearing Clinic, Punan Hospital, Shanghai.

\section{References}

1.Lethbridge-Cejku M, Schiller JS, Bernadel L. Summary health statistics for US adults: National Health Interview Survey, 2002. Vital Health Stat 10. 2004; 222:1-151.

2. Kim G, Na W, Kim G, Han W, Kim J. The development and standardization of

Self-assessment for Hearing Screening of the Elderly. Clin Interv Aging. 2016 Jun

$16,11: 787-95$.

3. Lin FR, Metter EJ, O'Brien RJ, et al. Hearing loss and incident dementia[J]. Arch Neurol, 2011, 68(2): $214 \rrbracket 220$.

4. Jayakody DMP, Almeida OP, Speelman CP, et al. Association between speech and high $\nabla$ frequency hearing loss and depression, anxiety, and stress in older adults[J]. Maturitas, 2018, 110: 86ख91.

5. Van Summers, Matthew J Makashay, Sarah M Theodoroff, Marjorie R Leek, Suprathreshold auditory processing and speech perception in noise: hearing囚impaired and normal囚hearing listeners[J]. J Am Acad Audiol, 2013, 24(4): $274 \llbracket 292$.

6. Öberg M, Marcusson J, Nägga K, et al. Hearing difficulties, uptake, and outcomes of hearing aids in people 85 years of age [J]. Int J Audiol, 2012, 51(2): 108ه115.

7. Deng XS, Ji F, Yang SM. Correlation Between Maximum Phonetically Balanced Word Recognition Score and Puretone Auditory Threshold in Elder Presbycusis Patients Over 80 Years Old [J]. Acta Otolaryngol, 2014, 134(2):168172.

8. Tomioka K, Ikeda H, Hanaie K, Morikawa M, Iwamoto J, Okamoto N, Saeki K,Kurumatani N. The Hearing Handicap Inventory for Elderly-Screening (HHIE-S) versus a single question: reliability, validity, and relations with quality-of-life measures in the elderly community, Japan. Qual Life Res. 2013 Jun;22(5):1151-9.

9. Labanca L, Guimarães FS, Costa-Guarisco LP, Couto EAB, Gonçalves DU. Screening of hearing in elderly people: assessment of accuracy and reproducibility of the whispered voice test. Cien Saude Colet. 2017 Nov;22(11):35893598.

10. Tomioka K, Ikeda H, Hanaie K,Morikawa M, Iwamoto J, Okamoto N, Saeki K,

Kurumatani N, The Hearing Handicap Inventory for Elderly-Screening (HHIE-S) versus a single question: reliability, validity, and relations with quality of life measures in the elderly community, Japan, Qual Life Res. 2013 Jun; 22(5):1151-9.

11. Diao MF, Sun JJ, Jiang T, et al ,Comparison between self-reported hearing and measured hearing thresholds of the elderly in China[J].Ear Hear, 2014, 35: 228. 
12. Tomioka K, Ikeda H, Hanaie K, et al. The Hearing Handicap Inventory for Elderly-Screening (HHIE-S) versus a single question: reliability, validity, and relations with quality of life measures in the elderly community, Japan. Qual Life Res, 2013,22(5): 1151-1159.

13. Laplante-Lévesque A, Brännström KJ, Ingo E, Andersson G, Lunner T, Stages of change in adults who have failed an online hearing screening, Ear Hear. 2015 Jan;36(1):92-101.

14. Saunders GH, Frederick MT, Silverman SC, Nielsen C, Laplante-Lévesque A, Description of Adults Seeking Hearing Help for the First Time According to Two

Health Behavior Change Approaches: Transtheoretical Model (Stages of Change) and

Health Belief Model, Ear Hear. 2016 May-Jun;37(3):324-33.

15. Chen Zhensheng, Duan Ji rong, Zhang Min, Yu Limei, Auditory rehabilitation of the elderly, Beijing ,Beijing Publishing House, 2010 March:1-255.

16. Han Demin, Xu Shiang, Wang Shufeng, Liu Bo, sun Xibin, Zhang Hua Basic and Clinical Audiology, Beijing ,Science and technology literature and Technology Press, 2004 April: 1-621.

17. Costa-Guarisco LP, Dalpubel D, Labanca L, Chagas MHN. Perception of hearing loss: use of the subjective faces scale to screen hearing among the elderly. Cien Saude Colet. 2017 Nov;22(11):3579-3588.

18. Charlotte L Allan, Sophie Behrman, Klaus P Ebmeier, Vyara Valkanova, Diagnosing early cognitive decline when, how and for whom? [J]. Matrritas, 2017, 96: 103-108.

19. Everett A, Wong A, Piper R, Cone B, Marrone N, Sensitivity and Specificity of Pure-Tone and Subjective Hearing Screenings Using Spanish-Language Questions. Am J Audiol. 2020 Feb 6:1-15.

20. Gates GA, Murphy M, Rees TS, et al. Screening for Handicapping Hearing Loss in the Elderly [J]. J Fam Pract, 2003, 52(1):56-62.

21. Arlinger S. Negative consequences of uncorrected hearing loss-a review. Int J Audiol. 2003;42(suppl 2): S17s20.

22. Jung $D$, Bhattacharyya N. Association of hearing loss with decreased employment and income among adults in the United States. Ann Otol Rhinol Laryngol. 2012;121(12):771- 775.

23. Kramer SE, Kapteyn TS, Kuik DJ, Deeg DJ. The association of hearing impairment and chronic diseases with psychosocial health status in older age. J Aging Health. 2002;14(1):122-137.

24. Perez E, Edmonds BA. A systematic review of studies measuring and reporting hearing aid usage in older adults since 1999: a descriptive summary of measurement tools. PLoS One. 2012;7(3): e31831.

25. Lin FR, Niparko JK, Ferrucci L, Hearing Loss Prevalence in the United states[J] Archives of Internal Medicine, 2011, 171(20): 1851- 1852】

26. Sarant J, Harris D, Busby P, Maruff P, Schembri A, Lemke U, Launer S. The 
Effect of Hearing Aid Use on Cognition in Older Adults: Can We Delay Decline or

Even Improve Cognitive Function? J Clin Med. 2020 Jan 17;9(1):254.

27.Ping He ,Xu Wen 1, Xiangyang Hu , Rui Gong 1, Yanan Luo , Chao Guo , Gong Chen , Xiaoying Zheng , Hearing Aid Acquisition in Chinese Older Adults with Hearing Loss. Am J Public Health. 2018 Feb; 108(2): 241- 247.

28.Paul Mick,M. Kathleen Pichora-Fuller, Is Hearing Loss Associated with Poorer Health in Older Adults Who Might Benefit from Hearing Screening? Ear and Hearing, 2016; 37(3): 194- 201.

29. Schneider J, Gopinath B, Karpa MJ, McMahon CM, Rochtchina E, Leeder SR, Mitchell P. Hearing loss impacts on the use of community and informal supports. Age Ageing. 2010;39(4):458-464. doi: 10.1093/ageing/afq051.

30. Carr SD, Moraleda J, Baldwin A, Ray J. Bone-conduction hearing aids in an

elderly population: complications and quality of life assessment. Eur Arch

Otorhinolaryngol. 2016 Mar;273(3):567-71. doi: 10.1007/s00405-015-3574-0. Epub

2015 Mar 4. PMID: 25736468.

31. Robert H Margolis 1, George L Saly, Chap Le, Jessica Laurence, Qualind: A method for assessing the accuracy of automated tests. Journal of the American Academy of Audiology, 2007, 18(1): 78-89.

32. Schulz S, Ritter J, Oertel K, Witt K, Bär KJ, Guntinas-Lichius O, Voss A.

Altered autonomic regulation as a cardiovascular risk marker for patients with

sudden sensorineural hearing loss. Otology and Neurotology, 2014, Dec;35(10):1720-9.

33. Labanca L, Guimarães FS, Costa-Guarisco LP, Couto EAB, Gonçalves DU. Screening of hearing in elderly people: assessment of accuracy and reproducibility of the whispered voice test. Ciencia Saude Colet. 2017 Nov;22(11):3589-3598.

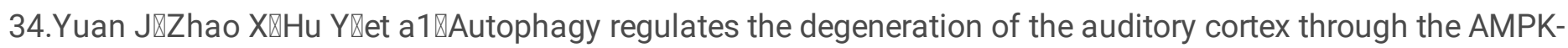
mTOR-ULK1 signaling pathway [J]『Int J Mol Med『2018ه4I (4): 2086- 2098.

35.Saunders GH, Frederick MT, Arnold ML,et al, Hearing Screening in the Community. J Am Acad Audiol, 2019 Feb;30(2):145-152.

\section{Figures}




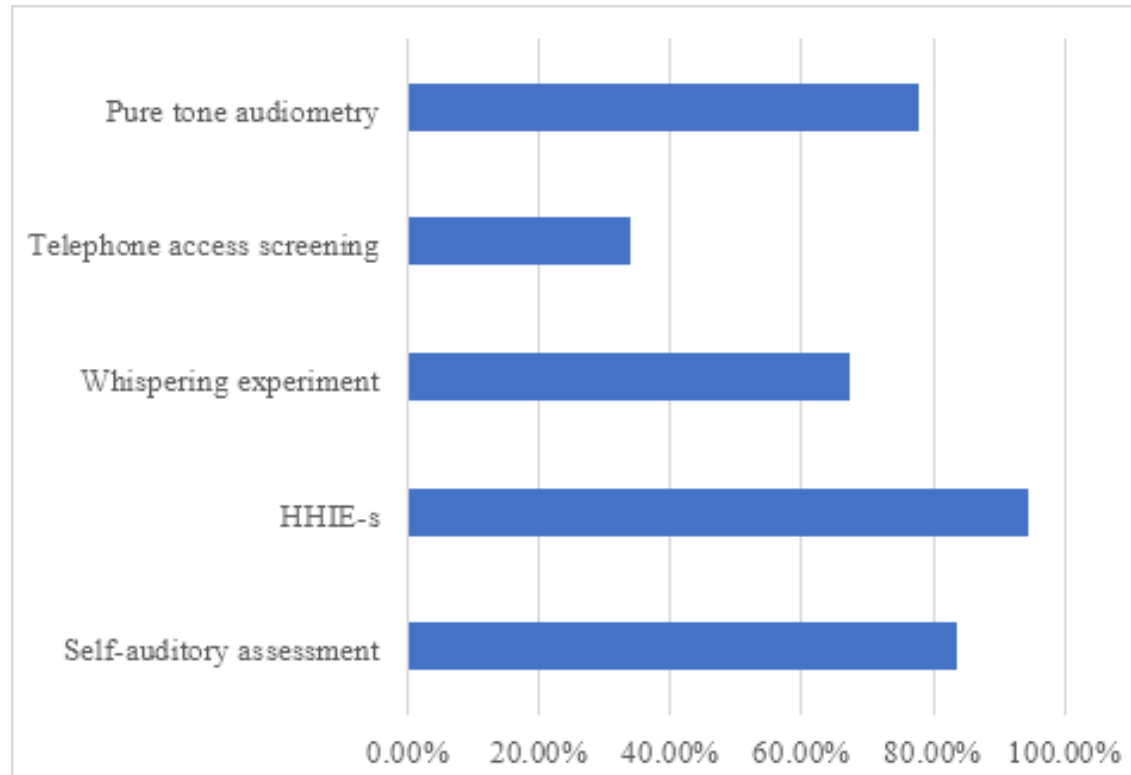

Figure 1

Screening of presbycusis

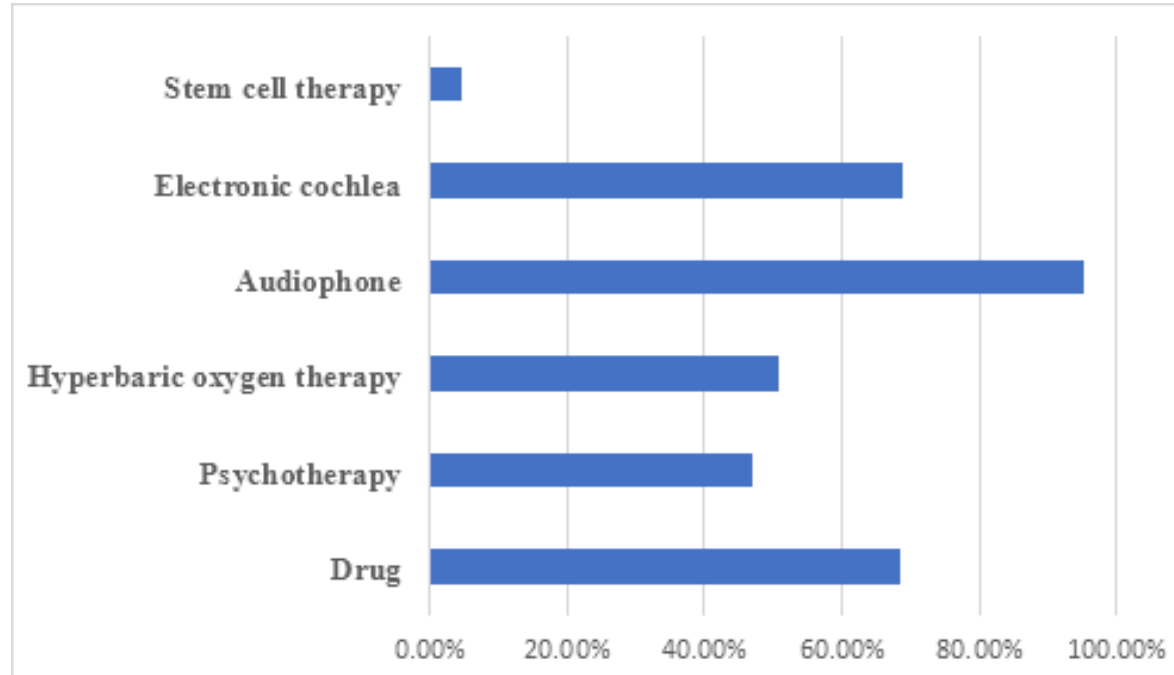

Figure 2

Screening of presbycusis

\section{Supplementary Files}

This is a list of supplementary files associated with this preprint. Click to download.

- Questionnaireforarticle.pdf 